\section{RAINHAS DA NOITE}

COELHO, João Paulo Borges. Lisboa: Caminho, 2013, 376 p.

Nazir Ahmed Can*

Rainhas da Noite, do moçambicano João Paulo Borges Coelho, dá continuidade a um projeto artístico que, a despeito de seu aparecimento tardio, em 2003, rapidamente se impôs como um dos mais instigantes dos contextos literários de língua portuguesa. Ambientado em dois espaços, Moatize e Maputo, e em dois períodos, o colonial e o pós-colonial, o romance descreve o modo como um caderno de memórias, escrito por Maria Eugénia Murilo, personagem recém-chegada da Metrópole nos estertores da década de 50, e encontrado pelo narrador em um mercado informal da capital cinquenta anos depois, dá lugar a uma investigação sobre o tempo e suas formas de confiscaçáo. $\mathrm{O}$ narrador, como se explicita no Prólogo, pressente nesse caderno a chave para um enredo. $\mathrm{O}$ que desencadeia seu empreendimento, no entanto, é o anúncio da morte de Maria Eugénia, publicado alguns meses depois por Travessa Chassafar, antigo empregado da au-

* Professor Adjunto de Literaturas Africanas de Língua Portuguesa, na Faculdade de Letras da Universidade Federal do Rio de Janeiro. tora, na página de necrologia do jornal Notícias. Eis aí os três protagonistas da história: uma narradora vinda do passado, um narrador inquieto mergulhado no presente e uma testemunha que transita como pode entre tempos.

Em um movimento raro na obra de Joáo Paulo Borges Coelho, mas com a desenvoltura que o caracteriza, o narrador cederá sua voz a uma figura feminina do passado, regressando no final de cada um dos nove capítulos que se seguem ao Prólogo, em uma pequena seção intitulada "Notas". No fito de interpretar as labirínticas linhas do caderno, bem como as hesitações, contradiçôes e não-ditos de $\mathrm{Ma}$ ria Eugénia, repensa os jogos de poder e até mesmo o horizonte de possíveis de uma minúscula comunidade que gravita em torno da Companhia carbonífera de Moatize. Uma decisiva divisão se anuncia nas memórias: enquanto os homens mostravam-se "entorpecidos pelo trabalho e por uma espécie de ingenuidade que os fazia sentirem-se responsáveis por todo aquele mundo, mas nada sabendo afinal o que verdadeiramente acontecia e importava" (p. 118), as mulheres sofriam uma espécie de degradaçáo, pois viviam em um lugar onde lhes "era vedada a possibilidade de exercerem a sua função mais fundamental, precisamente a de serem mulheres" (p. 71). A personagem-narradora não se referia, porém, às mulheres 
negras, escassamente inscritas no romance, e sempre a partir da perspectiva externa de quem as vê trabalhar, nem às mulheres da Metrópole, que dificilmente acederiam em sua terra aos privilégios do mundo colonial, mas à "nossa comunidade" (p. 44), isto é, às mulheres "como nós que, uma vez aqui chegadas nem sequer da casa podiam cuidar" (p. 71-72). Assim, embora se situe nesse tempo de assombrosas fendas em que "a raça contava porventura mais que tudo o resto" (p. 5253), e nesse espaço onde o "chão ruía a passos largos" (p. 155) devido à contestação que se iniciava contra a ordem vigente, após a administração decidir explorar o algodão, em detrimento do milho, agudizando desse modo o abismo entre patrôes e camponeses, Rainhas da Noite realçará o paradoxal lugar das mulheres brancas e as formas de violência intracomunitária por elas vividas em Moatize.

$O$ palco principal dessas figuras desbotadas no e pelo tempo será a Casa Quinze, onde vivem o senhor Simon, aristocrata belga, diretor-geral da Companhia, e sua esposa Annemarie, personagem influente, aracnídea, que toma todas as decisões importantes daquele reduzido núcleo. É ela a base da violência psicológica de que foi alvo, entre outros, Agnès Fink. Pianista premiada em Bruxelas, Agnès abandonou a Bélgica para acompanhar o marido em sua aventura africana, tendo depois se rebelado contra a paz podre do ambiente de Moatize. Seu desaparecimento é o episódio que mais envergonha o microcosmo colonial dessa localidade situada na província de Tete. De maneira fantasmática, estratégia utilizada por João Paulo Borges Coelho em outros romances (As Duas Sombras do Rio, Crónica da Rua 513.2, As Visitas do Dr. Valdez), sua lembrança rondará os recantos mais recônditos das restantes personagens, acentuando os segredos de uma narrativa que, com efeito, examina silêncios e silenciamentos. Por ter desnudado a "extrema arbitrariedade de Annemarie Simon e [a] extrema cobardia da pequena comunidade" (89), Agnès inspirará a trajetória de outras duas mulheres, Suzanne Clijsters e Maria Eugénia. A primeira, que tinha na compatriota sua principal referência, procurava distanciar-se do "ambiente afetado que reinava na sala da Casa Quinze” (p. 43). Todavia, com o passar do tempo, deixa notar que "mais que descobrir pretendia impressionar", tornando-se "vítima do seu hedonismo" (p. 179) e resvalando para aquilo que teorizava em suas conversas com Maria Eugénia: o tédio, "esse caminho a passos largos para a degradaçáo" (p. 72). A narradora das memórias, por sua vez, será vista pelo narrador das "Notas" como uma espécie de arquétipo da singularidade, como a face de um passado desconsiderado pela contemporaneidade moçambicana. De resto, o táo característico poder demiúrgico da figura autoral em João Paulo Borges Coelho, que neste romance volta a erguer espióes do passado para condenar o presente, não impede que, pela primeira vez em sua obra, uma personagem se sobreponha, em grau de importância, à figura do narrador. Maria Eugénia, detentora de uma sensibilidade capaz de abandonar "a lógica para seguir um fio misterioso", tendo assim chegado "à música das palavras", conduz o narrador a interrogar a história moçambicana, 
"a colocar as perguntas certas" (p. 368). Ainda que a hesitação e a contradição acompanhem seus passos, Maria Eugénia é uma heroína modelar, que se integra em uma obra pouco condescendente à atribuiçấo de exemplaridade a suas personagens. Joâo Paulo busca neste romance, enfim, detectar as "subtilezas que distinguiriam aquelas mulheres" (p. 179) e, por essa via, traçar o painel de um passado mais "rendilhado" do que o propagado pelos discursos do presente. Podemos afirmar inclusive que Rainhas da Noite dialoga, no que tange à temática, com um posicionamento que se tem robustecido no pensamento crítico e artístico dos últimos anos, especialmente em Portugal: o de ponderar a experiência colonial pelo olhar feminino para, através desse ângulo que tão pouco interesse despertou na historiografia, sondar alguns matizes do passado e identificar certos pontos cinzentos no interior da camada privilegiada.

A questấo do tempo e de seu manuseamento para fins diversos é, com efeito, uma preocupaçáo que atravessa o imaginário intelectual do autor moçambicano. Além de explicitada ("O mundo, velho ou novo, é o mesmo. Os que dizem o contrário sấo papagaios que vomitam uma retórica oca e mentirosa" - p. 245246) por um narrador que roça a impaciência por se sentir atropelado pelo "circo insano" (p. 358) do presente, ela é complementada neste romance por uma fina reflexão sobre os "reforços externos" que, neste caso, são utilizados para a leitura do passado. Se as fotos visam mostrar que "o meu texto não está isento de vulnerabilidades" e que, "ao obrigá-lo a partilhar o espaço com as imagens, a intenção não foi mais que aproximar o texto das minhas notas do texto do caderno, e com isso fazer uma espécie de vénia a este último" (p. 24), os documentos de arquivo são objeto de um enérgico escrutínio, pois representam o modo como o tempo é instrumentalizado segundo interesses específicos. Apesar de tentadores, pela abertura que favoreciam à pesquisa sobre o caderno de Maria Eugénia, os arquivos estavam "pejado de armadilhas" (p. 141): por um lado, criavam a ilusão de tudo abrangerem, mas, por outro, desconsideravam como "se escoam entretanto, e se perdem, os ódios e os amores. Os segredos" (p. 189). Por privilegiarem as narrativas hegemônicas, "destrinçando quem pertencia ao passado e de quem era o futuro" (p. 256), esses documentos distorciam o elo que poderia haver entre tempo e realidade: "Num deles, o objeto é por exemplo um Bernardo M'Boola desgastado, trémulo e doente, enquanto no seguinte o mesmo régulo é ainda jovem, ingénuo e confiante" (p. 219). Enquanto "fábrica de papéis, mas empenhada em trocar essa atividade pela produção do esquecimento" (p. 290), o arquivo passa a ser lido como um lugar de sujeira. As ratazanas que por lá pululam devem ser, por isso, interpretadas tanto em seu sentido literal quanto metafórico. $\mathrm{O}$ terceiro recurso utilizado, a testemunha, revela-se o mais complexo de todos. Travessa Chassafar, empregado da Casa Quinze e, depois, de Maria Eugénia, estabelece, como já referido, o elo entre passado e presente. $\mathrm{O}$ conhecimento que possuía, exterior ao do caderno, e a profissão que exercera ("nada melhor que os criados 
para espreitar atrás das barreiras erigidas em torno daqueles pequenos mundos privados" - p. 136) o tornava "numa espécie de senhor todo-poderoso" (p. 96). Contudo, seus encontros com o narrador são marcados pela oscilação característica de quem encontra na gestão da memória um mecanismo de defesa e, simultaneamente, um caminho para a transformação. A complexidade desse encontro será reiterada pelo narrador, que assume com insistência e de modo desabrido, pela adjetivaçáo, sua distância para com o universo cultural de Chassafar: "sua lógica enigmática" (p. 66); "punha em funcionamento a sua curiosa maneira de lembrar" (p. 186); "Na sua maneira circular de dizer as coisas" (p. 250).

Dois tempos, em suma, correm em paralelo no romance. Em primeiro lugar, o lento e arrastado período colonial de Moatize, composto por fantasmas, lutas surdas e gestos de diferenciação que, se por um lado, confirmam a contradição de um universo construído à volta de castas, por outro, visam tergiversar alguns dogmas erigidos no período que se seguiu à independência. Trata-se de um tempo marcado pela violência intracomunitária, que se indiciam nos tensos chás da Casa Quinze e se ampliam pelos rumores que "se espevitam e crescem neste lugar, como pequenos riachos serpenteando, achando caminhos entre as pedras para poderem engrossar" (p. 127-128), mas também pela natureza dessas rainhas da noite que, como a flor que inspira o título do romance, exalam mistérios que impedem sua totalização, são diversas e, pelo menos no quadro daquele limitado horizonte social, se mostram inquietas a ponto de buscarem um sentido que as salve da inutilidade. Em segundo, o extremo contemporâneo: aglutinando e desenvolvendo a narrativa primeira, o tempo atual abriga o abandono institucionalizado e a intensidade contraditória dos não-lugares urbanos, a dinâmica da ostentaçáo política e do desleixo civil e, sobretudo, a irritabilidade de um narrador perante o mundo que observa e o observa. De fato, o distanciamento entre o narrador e o espaço exterior é um traço que, perpassando a obra de João Paulo Borges Coelho, se agiganta neste romance.

Nesta narrativa coral que baralha as fronteiras do gênero (diário, crônica, ensaio, romance, romance histórico, romance policial) demarcando gêneros (feminino e masculino), e entrecruza, reavaliando-as, diversas fontes de investigação (caderno de memórias, fotografias, arquivo, testemunha), João Paulo Borges Coelho questiona a hierarquia e a legitimidade dos relatos sobre a passagem do tempo, desempoeira do passado algumas linhas de continuidade com o presente e radicaliza um posicionamento intelectual que, partindo da e celebrando a literatura, faz da discussão sobre a memória e a história sua pedra angular.

\section{Referências bibliográficas:}

COELHO, João Paulo Borges. Rainhas da Noite. Lisboa: Caminho, 2013. Nome: (Universidade Federal do Rio de Janeiro). 